\title{
Effect of Cuminum Cyminum L. Oil on the Chemical Properties of Sunflower Reused Oil
}

\author{
Amina Abdelrhim Belal, Faroug Bakheit Mohamed Ahmed \\ Faculty of Science and Technology, University of Shendi, Shendi, Sudan \\ Email address: \\ farougmhmd@gmail.com (F. B. M. Ahmed) \\ To cite this article: \\ Amina Abdelrhim Belal, Faroug Bakheit Mohamed Ahmed. Effect of Cuminum Cyminum L. Oil on the Chemical Properties of Sunflower \\ Reused Oil. Journal of Food and Nutrition Sciences. Vol. 5, No. 4, 2017, pp. 162-166. doi: 10.11648/j.jfns.20170504.14
}

Received: February 25, 2017; Accepted: March 15, 2017; Published: July 12, 2017

\begin{abstract}
This study was designed to determine the influence of extracted oil of Cuminum Cyminum on the chemical properties of reused Sudanese edible oil (sunflower oil). Green cumin oil was extracted from its mature seeds by water-steam distillation process. The chemical profile of cumin oil was detected by using GC-MS. The analysis showed that the chemical constituents of oil were; monoterpens percentage was $33.09 \%$ and oxygenated monoterpens percentage was $66.91 \%$. Chemical properties of sunflower oil were tested before and after several repeated cooking processes, and after addition of extracted cumin oil. The cumin oil had positive effect on the chemical properties values; peroxide, acidity, free fatty acids value and there were significant differences for these three properties $(p<0.05)$. The study was attributed the high effect of cumin oil on the chemical properties mainly to antioxidant constituents in the extracted oil monoterpens and oxygenated monoterpens.
\end{abstract}

Keywords: Cumin, Reused Oil, Peroxide, Free Fatty Acids, Monoterpens

\section{Introduction}

Cuminum Cyminum $L$ is an herbaceous and medicinal crop and one of the oldest and popular seed spice [1]. The term 'spice' originated from the Latin word 'species', meaning of specific kind [2]. Spices can be used in foods as antioxidants. They help fight the toxins created by our modern world. [3]. Cumin (Cuminum cyminum) is a flowering plant in the family Apiaceae, native from the east Mediterranean to East India [4]. Cumin is popularity spread from Latin America to Africa and all over Asia [5].

The cumin plant grows to $30-50 \mathrm{~cm}$ tall and is harvested by hand. It is an annual herbaceous plant, with a slender, branched stem $20-30 \mathrm{~cm}$ tall. It has blue-green linear leaves and finely separated. The white or pink flowers are borne in small compound umbels [6]. In fact, cumin is one of the most important crops in terms of exports, income, water use efficiency and reclamation of the arid and semiarid regions [7]. Cumin seed is generally used as a spicy food in the form of powder for imparting flavor to different food preparations [8].

The constituents of cumin oil were differing according to the area from which the cuminum cyminum samples were taken. Green cumin seeds yield, crude protein $18.40 \pm 0.16$ and $19.88 \pm 0.20 \%$, crude fibers $21.82 \pm 0.13$ and $23.57 \pm$
$0.13 \%$, total carbohydrate 55.58 and $60.05 \%$ in the wet and dry fruits respectively [9]. Cumin also contains very good amounts of B-complex vitamins and other vital anti-oxidant vitamins like vitamin $\mathrm{E}$, vitamin $\mathrm{A}$ and vitamin $\mathrm{C}$. In addition, the seeds yield numerous free amino acids, and a variety of flavonoidglycosides, including derivatives of apigenin and luteolin [10].

In traditional herbal medicine cumin was used to treat hoarseness, jaundice, dyspepsia and mixed with other ingredients to treat diarrhea and colic [11]. Oral administration of Cumin for 6 weeks to diabetic rats resulted in significant reduction in blood glucose and body weight [12]. In a glucose tolerance test conducted in rabbits cumin significantly increased the area under the glucose tolerance curve and hyperglycemic peak [13].

An antioxidant is a molecule that inhibits the oxidation of other molecules. Oxidation is a chemical reaction that can produce free radicals, leading to chain reactions that may damage cells $[14,15]$. These oxidative reactions result in a partial loss of minor constituents, primary cause of the health-promoting effects of oil consumption [16, 17]. Cumin have good antioxidant potential and this spices can be used to produce novel natural antioxidants as well as flavoring agents that can be used in various food products [18]. 
Sunflower oil is non-volatile oil compressed from the sunflower seeds (Helianthus Annuus). Sunflower oil is commonly used in food as frying oil, and in cosmetic formulations as an emollient [19]. Depending on the type of oil, its age, storage conditions, etc., peroxide value is good indicators of oil rancidity. The peroxide value is the number that expresses, in milli alcoholic potassium hydroxide solution prepared by dissolve equivalent of active oxygen [20]. According to National Renderers Association [21] peroxide value of fresh and well processed oils should show be less than 12 . One measure of fat quality is the free fatty acid (FFA) content. Therefore the presence of high levels of FFA indicates the fat was exposed to water, acid, and/or enzymes [22].

Fats undergo changes during storage which result in the production of an unpleasant taste and odor, which is commonly referred to as rancidity is brought about by the action of air (oxidative rancidity) or by microorganisms (ketonic rancidity) [23]. Oxidation primarily occurs with unsaturated fats. Via a free radical process, the double bonds of an unsaturated fatty acid can undergo cleavage, volatile aldehydes and ketones. There are some factors influencing fat oxidation [24]:

Temperature: The rate of fat oxidation is highly dependent on temperature. Considerable improvement in storage stability can therefore be gained by lowering the storage temperature. As an example, it has been found that the storage time for frozen raw, lean meat can be extended approximately by 3 times by lowering the temperature from 15 to $-25^{\circ} \mathrm{C}$.

Oxygen: Oxygen in the air may be displaced by an inert gas such as nitrogen or carbon dioxide to retard oxidative rancidity, or the products may be packed under vacuum. These methods require the use of packaging materials with low oxygen permeability.

Type of fat: In general, the softer the fat, the more unsaturated are the fatty acids and the more susceptible they are to oxidation and oxidative rancidity. However, vegetable fats, although unsaturated, are usually more stable than animal fats because they contain natural antioxidants. The most common antioxidant found in vegetable fats is vitamin $\mathrm{E}$.

Light: Packages that exclude light can be used to protect the products against fat oxidation.

Metals: Metals such as copper, iron, manganese, and chromium increase rate of fat oxidation. As a result, the preferred storage containers are steel drums, tin, or nonmetallic materials such as plastic.

Products from fat oxidation: Traces of oxidized fat in ingredients can accelerate oxidative rancidity in the remainder of the products. Steam treatment under vacuum conditions has been effective in removing products of deterioration (odorous substances) from some oils and fats.

The present study conducts to determine the chemical profile of Cuminum Cyminum oil and its effect on the chemical properties of reused oil of Sudanese edible oil (Sunflower).

\section{Samples Preparation}

Cumin seeds were purchased from Shendi local market obtained in the crop season 2015 - 2016, while the modern product sample of sunflower oil was purchased from Arabian Oils Company, Khartoum, Sudan.

\section{Material and Method}

\subsection{Distillation of Cumin Seeds}

Cumin Cyminum oil was extracted by water- steam distillation. Cumin seeds were put into an alembic over water, then the water was heated, the steam passed through the Cumin seeds, vaporizing the volatile compounds. The vapors flowed through a coil, where they were condensed back to liquid, which is then collected in the receiving vessel. At the end of the distillation process cumin oil was separated from water depending on the difference in their density by using laboratory separating funnel. The cumin oil was collected in dark pure bottle and had been ready to determine its chemical profile and others tests.

\subsection{Chemical Profile}

Cumin oil was analyzed by using a gas chromatography mass spectroscopy (GCMS- QP 2010 plus) equipped with selective detector mass spectroscopy. Operating condition for $\mathrm{GC}$ were: injection temperature $250^{\circ} \mathrm{C}$, pressure $61.8 \mathrm{kpa}$, total flow $364 \mathrm{ml} / \mathrm{min}$, column flow $1.2 \mathrm{ml} / \mathrm{min}$, linear velocity $39.4 \mathrm{~cm} / \mathrm{sec}$ and oven temperature $35.0^{\circ} \mathrm{C}$ for 3 minutes and held $280^{\circ} \mathrm{C}$ for 4 minutes; mass spectroscopy operating parameters were: ion source temperature $250^{\circ} \mathrm{C}$, interface temperature $250^{\circ} \mathrm{C}$, solvent cut time 3.50 minutes, detector gain mode relative, threshold 0 ; and mass spectroscopy table scan $\mathrm{m} / \mathrm{z}$ range from $35-800$. The identification of oil constituents was carried out by comparing retention times with those of authentic reference compounds, or peak matching library research using the standard mass library (NIST147 \& WILEY7).

\subsection{Determination of Chemical Properties}

a. Peroxide value: It is defined as the milliequivalents of peroxide per $\mathrm{kg}$ of sample. The assumption is made that the compounds reacting under the condition of the test are peroxides or similar product of lipid oxidation. Upon addition of excess potassium iodide reacts with the peroxide, iodine is produce. Through titration process, iodide reacts with standardized sodium thiosulfate using a starch indicator. Oil sample ( $3 \mathrm{~g})$ was weighed into a $250 \mathrm{ml}$ brown glass beaker and placed onto the sample rack. $20 \mathrm{ml}$ solvent mixture [ethanol, acetic acid 3: 2] and $1 \mathrm{ml}$ concentrated potassium iodide were added then the beaker was closed and kept for 5 minutes. After that I $\mathrm{ml}$ of starch and $80 \mathrm{ml}$ distilled water were added and the solution was titrated with $\mathrm{Na}_{2} \mathrm{~S}_{2} \mathrm{O}_{3}(0.001 \mathrm{~mol} / \mathrm{l})$ until the end point. 


$$
\begin{gathered}
\mathrm{ROOH}+\mathrm{KI} \stackrel{\mathrm{H}^{+}, \text {heat }}{\longrightarrow} \mathrm{ROH}+\mathrm{KOH}+\mathrm{I}_{2} \\
\mathrm{I}_{2}+\operatorname{strach}(\text { blue })+2 \mathrm{Na}_{2} \mathrm{~S}_{2} \mathrm{O}_{3} \\
\longrightarrow 2 \mathrm{NaI}+\mathrm{Na}_{2} \mathrm{~S}_{4} \mathrm{O}_{6}+\operatorname{strach} \text { (colorless) }
\end{gathered}
$$

b. Acid value: Acid value of oil is the number of $\mathrm{mg}$ of potassium hydroxide necessary to neutralize the free acid in $1 \mathrm{~g}$ of the sample. The reaction is accelerated by heat and light. $25 \mathrm{ml}$ diethyl ether was mixed with 25 $\mathrm{ml}$ ethanol and $1 \mathrm{ml}$ phenolphthalein solution $1 \%$ and then carefully neutralized with $0.1 \mathrm{~N}$ alkali. Oil sample was dissolved in the neutral solvent, the mixture was shaking constantly until a pink color which persisted for 15 second was obtained and then titrated with aqueous sodium hydroxide $(0.1 \mathrm{~N})$.

$$
\mathrm{RCOOH}+\mathrm{KOH} \rightarrow \mathrm{RCOOK}+\mathrm{H}_{2} \mathrm{O}
$$

c. Free fatty acid: Measure of fat acidity is normally reflecting the amount of fatty acids hydrolyzed from triacylglycerol. In samples containing no acids other than fatty acids (no acid phosphates or amino acids), free fatty acid and acid value may be converted from one to the other using conversion factors.

$$
\text { Free fatty acid }=\text { Acid Value } / 2
$$

\subsection{Statistical Analysis}

Statistical analysis was done by using SPSS programme under windows (IBM) computer system. The confidence limit was $95 \%$, the $\mathrm{p}$ value was considered to be significant at value of $\leq 0.05$.

\section{Results}

The GC- MS analysis of cumin oil showed that eleven constituents were identified; seven hydrocarbon monoterpens (33.09\%) and four oxygenated monoterpens $(66.92 \%)$. The monoterpens were $\alpha$-Thujene $0.41 \%, \alpha$-pinene $0.90 \%, \beta$ pinene $10.72 \%, \beta$-myrcene $1.27 \%$, $\alpha$-phellandrene $1.18 \%, p$ cymene $3.54 \%$ and $\gamma$-terpinene $15.07 \%$, and oxygenated monoterpens identified were cumin aldehyde $21.10 \%$,

\begin{tabular}{|c|c|c|c|c|c|}
\hline Terpene Type & Constituent & Percentage $\%$ & Retention Time & Base peak & Mass Peak \\
\hline \multirow{7}{*}{ Monoterpens } & $\alpha$-Thujene & 0.41 & 10.56 & 93.10 & 383 \\
\hline & $\alpha$-Pinene & 0.90 & 10.783 & 93.10 & 396 \\
\hline & $\beta$-Pinene & 10.72 & 12.275 & 93.10 & 417 \\
\hline & $\beta$-Myrcene & 1.27 & 12.750 & 93.10 & 418 \\
\hline & $\alpha$-Phellandrene & 1.18 & 13.175 & 93.10 & 348 \\
\hline & $p$-Cymene & 3.54 & 13.875 & 119.15 & 389 \\
\hline & $\gamma$-Terpinene & 15.07 & 15.042 & 93.10 & 325 \\
\hline \multirow{4}{*}{$\begin{array}{l}\text { Oxygenated } \\
\text { monoterpens }\end{array}$} & Cumin aldehyde & 21.10 & 20.708 & 133.15 & 380 \\
\hline & Carboxaldehyde & 5.43 & 19.225 & 109.10 & 392 \\
\hline & 2-Caren-10-al & 17.74 & 21.958 & 97.10 & 382 \\
\hline & Cumin alcohol & 22.65 & 22.175 & 107.10 & 389 \\
\hline
\end{tabular}
Carboxaldehyde 5.34\%, 2-Caren-10-al $17.74 \%$ and cumin alcohol $22.65 \%$. Table 1 represented the results of GC-MS analysis.

Table 1. The chemical constituents of cumin oil analyzed by gas chromatography.

Chemical properties of oil; peroxide value (PV), acid value (AV) and free fatty acid (FFA) were determined for new sample of sunflower oil and volatile cumin oil, Table 2

Table 2. The chemical properties of new sunflower oil and volatile cumin oil.

\begin{tabular}{llll}
\hline Oil type & Peroxide value & Acid value & $\begin{array}{l}\text { Free fatty } \\
\text { acids }\end{array}$ \\
\hline Sunflower oil & 2.00 & 0.93 & 0.47 \\
Volatile cumin oil & 1.69 & 0.17 & 0.08 \\
\hline
\end{tabular}

Other new sample of sun flower oil was subjected for repeated cooking processes (reused oil), then $3 \mathrm{~g}$ of reused oil was prepared to investigated obvious chemical properties. To determine the effect of cumin oil $0.5 \mathrm{ml}$ of extracted cumin oil was added to $3 \mathrm{~g}$ of reused sunflower oil and then mixture subjected to investigation the mentioned chemical properties. Table 3 .
Table 3. Chemical properties of re-used oil before and after addition of cumin.

\begin{tabular}{llll}
\hline Chemical property & Peroxide value & Acid value & $\begin{array}{l}\text { Free fatty } \\
\text { acids }\end{array}$ \\
\hline Re-used oil & 36 & 0.54 & 0.27 \\
Re-used oil $+0.5 \mathrm{ml}$ & 9 & 0.26 & 0.13 \\
P value & $<0.05$ & $<0.05$ & $<0.05$ \\
\hline
\end{tabular}

\section{Discussion}

Due to the enormous amount of raw product used to make wholly natural essential oils, it is important to study the chemical composition of the volatile fraction once the essential oil is extracted. This fraction is characterized by the complexity in the separation of its components, which belong to various classes of compounds and which are present in a wide range of concentrations. Therefore it is complicated to 
establish a composition profile of essential oils. The gas chromatographic method (GC) is almost exclusively used for the qualitative analysis of volatiles. The GC-MS analysis showed that the chemical constituents of oil were; monoterpens percentage was $(33.09 \%)$ and oxygenated percentage was $66.91 \%$. Comparison of our data with data from other studies, cuminaldehyde of our result $(21.10 \%)$ was lower than that results reported by Baser, et al., 1992 [25] in Turkey, Maowad, et al., 2005 [9] in Egypt and Hajlaoui, 2010 [26] in Tunisia who found cuminaldehyde percentage was $25 \%, 35.25 \%$ and $39.48 \%$ respectively and higher than that reported by Chaudhary, 2014 [27] in Delhi which found it $0.33 \%$ only. The possible explanation of the varieties in the previous percentages may be due to differences in soil type, climate, agriculture and irrigation system, and distillation process.

Several studies utilizing herbs, spices, fruits and vegetable extracts, and have shown that addition of these extracts to raw and cooked meat products decreased lipid oxidation [28]. The study was appeared evident increase in the chemicals properties values; peroxide value, acid value and free fatty acid value of sunflower oil after used it several times in cooking processes (reused oil) (1.6 to 36$),(0.17$ to 0.54 ) and ( 0.04 to 0.27 ) respectively. That might be explained due to the effect of frying oil boiling and then cooled and reused it again which result in chemical changes that occur as a result of break-up during boiling and decomposition of food and which thus result in the oxidation process. sunflower oil is softer oil and more susceptible to oxidation because it contains double bond of unsaturated fatty acids that became aldehyde, ketones and peroxides, and when peroxides concentration reached a certain level, complex chemical changes occurred and volatile oil products were formed. After addition of cumin oil there was a clear drop in the values compared to the values of the reused oil before the addition, (36.00 to 9.00$),(0.54$ to 0.26$) \&(0.27$ to 0.13$)$ for peroxide value, acid value and free fatty acids value respectively. Therefore our study showed that there is a clear impact of the extracted oil on the previous three chemical properties of reused sunflower oil $(\mathrm{p}<0.05)$. That could be explained by the presence of antioxidant compounds that were found in the cumin oil and detected in this study by gas chromatography monoterpens and oxygenated monoterpens. This was reflected the high impact of the cumin oil on the reused oil and improves its chemical properties and thus reduces the excess severity on human health. The essential oils of herbs and spices are widely known for their strong antioxidant in foods [29].

\section{Conclusion and Recommendations}

Cumin oil was extracted and analyzed and chemical constituents were monoterpens and oxygenated compounds. Chemical properties of sunflower oil were studied at the beginning, after repeated cooking process and after addition of cumin oil. The study found that cumin oil has an impact on chemical properties of reused oil. Cumin Cyminum oil contains number of antioxidants compounds that will make it good source in preservation of foods and oils against rancidity oxidative.

\section{References}

[1] Divakara S. E. V. and Anandara J M. (2013): Cumin, fennel and fenugreek, soils, plant growth and crop production. Encyclopedia of life support systems (EOLSS).

[2] Nazeeem, P. A. (1995). The spices of India. The Herb, Spice, and Medicinal Plant Digest 13(1): 1-5.

[3] Raghavan, S. (2007). Handbook of spices, seasonings, and flavorings. $2^{\text {nd }}$ Ed. CRC Press, Taylor \& Francis Group, Boca Raton.

[4] Zohary, D. and M. Hopf. 2000. Domestication of plants in the Old World. 3rd Ed. Oxford University Press, p. 206.

[5] Anonymous, (2008). The Siddha Pharmacopoeia of India. Govt. of India, Ministry of Health \& Family Welfare, New Delhi.Part I, Vol. I.

[6] Weiss, E. A. (2002). Umbelliferae. In: spice crops. CAB International, walling ford, UK, pp. 261.268.

[7] Tuncturk, R. and Tuncturk, M (2006). Effects of different phosphorus levels on the yield and quality components of cumin (Cuminum Cyminum L.). Research journal of Agriculture and biological sciences, 2, 336-40.

[8] Kafie, M., Rashed-Mohasel M. H., Koocheki, A., Nassiri,M.(2002). Cumin (Cuminum Cyminum L.) productionand processing, Ferdowsi University Press, Iran.P 168.

[9] Moawad, S. A., (2015) El-Ghorab, A. H., Hassan. M., NourEldin H. and El-Gharabli, M. M. Chemical and microbiological characterization of Egyptian cultivars for some spices and herbs commonly exported abroad. Food and Nutrition Sciences; 6: 643-659.

[10] Ishikawa T., Takayangi T., and Kitajima J. (2002). Watersoluble constituents of cumin: monoterpens glucosides. Chem Pharm. Bull (Tokyo); 50(11): 1471-78.

[11] Parthasarathy, V. A., Chempakam B and Zachariah T. J. (2008). Chemistry of spices. CAB International: 211-16.

[12] Katan. J., Fishler. G., Grinstein. A. (2011). Short and long term effects of soil polarization and crop sequence on Fusarium wilt and yield of cotton in Isreal. Phtopathology 73: 1215-19.

[13] Razzaghi, A. M, Shams, G. M, Rezaee M. B., Jimand K., Alinezahad S., and Saberi R. (2009). Chemical composition and antiaflatoxigenic activity of Carum carvi L, Thymus vulgaris and Citrus aurantifolia essential oils. Food Contr.; 20: 1018-24.

[14] Chen B. H., Huang J. H., (1998). Degradation and isomerization of chlorophyll a and beta-carotene as affected by various heating and illumination treatments. Food Chem., 62, 299-307.

[15] Manna C., Galletti P., Cucciolla V., Moltedo O., Leone A., and Zappia V., (1997). The protective effect of the olive oil polyphenol (3, 4- Dihydroxyphenyl) Ethanol counteracts reactive oxygen metabolite-induced cytotoxicity in caco-2 cells. J. Nutr., 127, .29-286. 
[16] Psomiadou E., Tsimidou M., (2002). Stability of virgin olive oil. 1. Autoxidation studies. J. Agric. Food Chem., 50, 716-72.

[17] Visoli F. and Galli C., (1998). Olive oil phenols and their potential effects on human health. J. Agric. Food Chem., 46, 492-429.

[18] Nadeem, M. and Riaz A. (2012). Cumin (Cuminum cyminum) as a potential source of antioxidants. Pak. J. Food Sci., 22(2), pp: 101-105.

[19] FAO (2015). Food Agriculture Organization. Food Outlook, www.fao.org/.htm.

[20] Ekwu A. and Nwagu, F. C. (2004). Effect of processing on the quality of cashew nut oils J. Sci. Agric. Food Tech. Environ., 4, pp. 105-110.

[21] National Renderers Association. (2003). Pocket information manual abuyer's guide to rendered product $\mathrm{p}$ Published by National Renderers Association. Inc. pp $18-28$.

[22] Powels J., Wiseman J., Cole D. J. A. and Jagger S. (1995). Prediction of the apparent digestible energy value of fats given to pigs. Anim Sci.; 61: 149-154.

[23] Porter, N. G. and Lammerink, J. P., (1994). Effect of Temperature on the Relative Densities of Essential Oils and Water. J. Essent. Oil. Res., 6, 269-277.

[24] Sebranek, G. J., Neel.S., (2008).Rancidity and Antioxidants.
WFLO Commodity Storage Manual. World Food Logistics Organization, for the review and revision of this topic. pp 1-3. http://www.gcca.org/wpcontent/uploads/2012/09/RancidityAntioxidants.

[25] Baser.K. H., Kurkcuoglu. M and Ozek T. (1992). Composition of the Turkish cumin seed oil. Journal of Essential Oil Research 4 (2): 133-38.

[26] Hajlaoui H., Mighri, H., Noumi E., Snoussi M. Trabelsi N. and Ksouri R. (2010). Chemical composition and biological activities of Tunisian Cuminum cyminum L.essential oil: A high effectiveness against Vibriospp. strains. Food Chem Toxicol; 48:(2), 861-921.

[27] Chaudhary N, Husain,S. S. and Ali. M., (2014). Chemical composition and antimicrobial activity of cumin oil (Cuminum cyminum, Apiaceae). Journal of Pharmacy and Pharmaceutical Sciences; 3(7): 1428-41.

[28] Zhang, M., Baerdemaeker, J., and Schrevens, E. (2010). Effects of different varieties and shelf storage conditions of chicory on deteriorative color changes using digital image processing and analysis. Food research international; 36(7), 669-76.

[29] Hygreeva D., Pandey M., Radhakrishna K. (2014). Potential applications of plant based derivatives as fat replacers, antioxidants and antimicrobials in fresh and processed meat products. Meat. Science, (1)98 p. 47-57. 